\title{
The Nutrition Transition: New Trends in the Global Diet
}

\author{
Adam Drewnowski, Ph.D., and Barry M. Popkin, Ph.D.
}

\begin{abstract}
Analyses of economic and food availability data for 1962-1994 reveal a major shift in the structure of the global diet marked by an uncoupling of the classic relationship between incomes and fat intakes. Global availability of cheap vegetable oils and fats has resulted in greatly increased fat consumption among low-income nations. Consequently, the nutrition transition now occurs at lower levels of the gross national product than previously, and is accelerated further by high urbanization rates. Data from Asian rations, where diet structure is rapidly changing, suggest that diets higher in fats and sweeteners are also more diverse and more varied. Given that preferences for palatable diets are a universal human trait, fat consumption may be governed not by physiological mechanisms but by the amount of fat available in the food supply. Whereas economic development has led to improved food security and better health, adverse health effects of the nutrition transition include growing rates of childhood obesity. The implications of these trends are explored.
\end{abstract}

\section{Introduction}

Wealth and poverty have profound effects on diets, nutrition, and health. Economic factors have a far broader influence on global eating habits than might be expected from the analysis of dietary trends in developed nations. As incomes rise and populations become more urban, societies enter different stages of what has been called the nutrition transition. ${ }^{1,2}$ Generally, diets high in complex carbohydrates and fiber give way to more varied diets with a higher

Dr. Drewnowski is Professor and Director, Program in Human Nutrition, School of Public Health, University of Michigan, Ann Arbor, Michigan, USA. Dr. Popkin is Professor of Nutrition, School of Public Health, University of North Carolina, Chapel Hill, North Carolina, USA.

Direct correspondence to Dr. Popkin at the Carolina Population Center, University Square, 123 W. Franklin St., University of North Carolina at Chapel Hill, Chapel Hill, NC 27516-3997 (e-mail: popkin@unc.edu). proportion of fats, saturated fats, and sugars..$^{3-5}$ These shifts in diet structure accompany demographic shifts associated with higher life expectancy and reduced fertility rates. An associated epidemiologic transition also takes place as patterns of disease shift away from infectious and nutrient deficiency diseases toward higher rates of coronary heart disease and some types of cancer. ${ }^{1-2,6,7}$ The nutrition transition has also been associated with a higher prevalence of obesity, particularly childhood obesity, and non-insulindependent diabetes. ${ }^{8,9}$

To some health professionals, adverse health effects of the nutrition transition represent a deplorable by-product of economic growth. ${ }^{10}$ In some cases, the "Westernization" of global eating habits has been singled out for special blame. Food imports, fast foods, and a rising consumption of sugars and animal fats are sometimes held to be responsible for the rising global rates of obesity and associated chronic disease. ${ }^{10-11}$ A major dilemma facing the health and nutrition profession in any country, as well as the World Bank, USAID, and other agencies for international development, is how best to promote economic growth and prevent or delay the undesirable health effects of the nutrition transition. Providing a better understanding of the links between economic factors, demographic variables, and food consumption trends in developing nations is the main purpose of this review.

The strength of the association between incomes and diet structure at national and individual levels will be our principal theme. The key question relates to the likely success of nutrition policies and programs aimed at the developing world. Wealthy industrialized nations in North America and the European Union spend spend significant sums of money to convince their citizens to replace dietary fats with a simpler diet based on grains, vegetables, and fruit. ${ }^{12-14}$ Paradoxically, developing nations use their growing incomes to replace their traditional diets, rich in fibers and grains, with diets that include a greater proportion of fats and caloric sweeteners. This global paradox in the making can also be observed within countries. One documented incongruity in the current American diet is that higher-income and more educated groups are consuming diets more akin to those of lower-income groups in the post-World War II period. ${ }^{15}$ Given the globalization of the human diet, the nature of the connection between incomes 


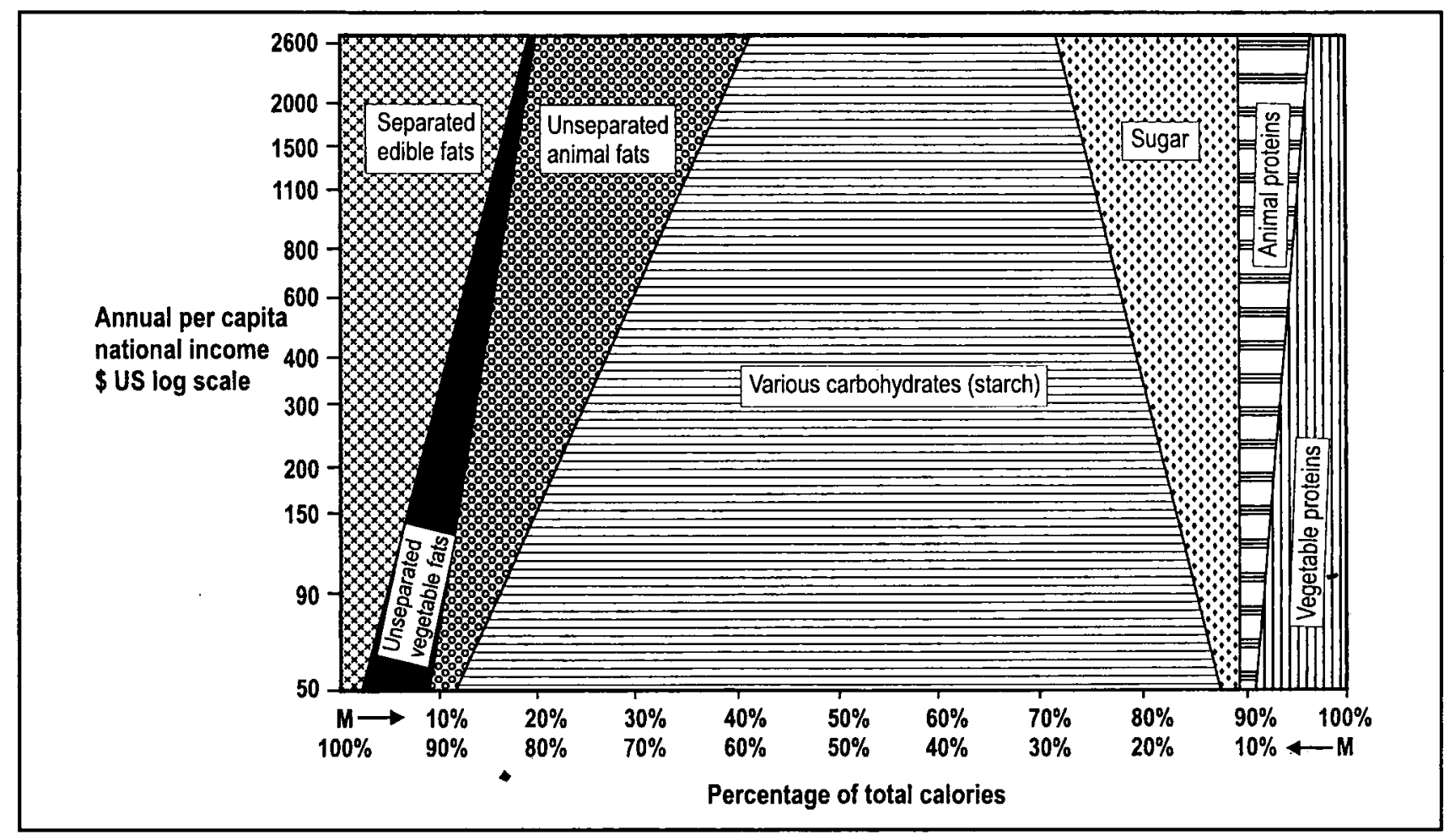

Figure 1. Structure of the diet and income (country-level sources of energy, 1962).

and diet structure is an issue of economic and public health interest.

Whereas high-fat diets and Western eating habits were once restricted to the rich industrialized nations, we present new evidence that the nutrition transition now occurs in nations with much lower levels of gross national product (GNP) than previously. Even low-income societies now have access to a high-fat diet. In this review, we add a focus on the impact of rapid urbanization as we explore some of the underlying shifts in global dietary habits and food consumption trends. To put the enormity of these changes in context, we present data that provide a very clear warning about the potential consequences of the accelerated nutrition transition for child health, especially among the urban poor.

\section{Incomes and Diet Structure}

Diets high in fats, especially meat and milk products, used to be tied to a high level of income, whether at the national or the individual level. A direct relationship between the GNP per capita and the global diet structure was documented three decades ago in a classic study. ${ }^{3,4}$ As shown in Figure 1, analysis of food balance sheets from the Food and Agriculture Organization (FAO) ${ }^{4}$ of the United Nations for 85 countries in 1962 showed that high GNP levels were associated with greater percentages of energy derived from sugars and from vegetable and animal fats. Although the proportion of energy from protein remained constant, diets of rich nations were largely based on animal rather than vegetable proteins. The proportion of energy from complex carbohydrates diminished sharply as a function of growing incomes, a characteristic feature of the nutrition transition. Subsequent analyses by Chevassus-Agnes ${ }^{5}$ of FAO that included data from later years confirmed this direct link between log GNP and the proportion of energy from fats.

We provide new evidence that the structure of the income-diet relationship has undergone a significant change. First, fat consumption is less dependent on GNP than ever before. Second, rapid urbanization has a major influence in accelerating the nutrition transition. ${ }^{16,17}$ Our analyses were based on sequential FAO food balance sheets for the period 1962-1990, now available in the FAOSTAT database. ${ }^{18}$ We combined data on food availability, expressed in percentage of daily energy from macronutrients, with the official estimates of GNP as established by the World Bank. ${ }^{19}$ In both cases, GNP per capita was expressed in 1993 dollars to allow for an easier comparison of the results. Regression analyses were used to relate dietary data (the proportion of energy from vegetable and animal fats, carbohydrates, caloric sweeteners, and protein) for those countries for which full sets of data were available in 1962 and in 1990 to the logarithm of per capita GNP. This research used all countries for which both sets of data were available. These numbered 98 in 1962 and 133 in 1990 . When alternative samples that consisted of countries with full sets of data in both 1962 and 1990 were compared, the results were identical.

The regression analysis also included an urbanization variable. Although GNP and the extent of urbanization were closely linked before World War II, this is clearly no longer 


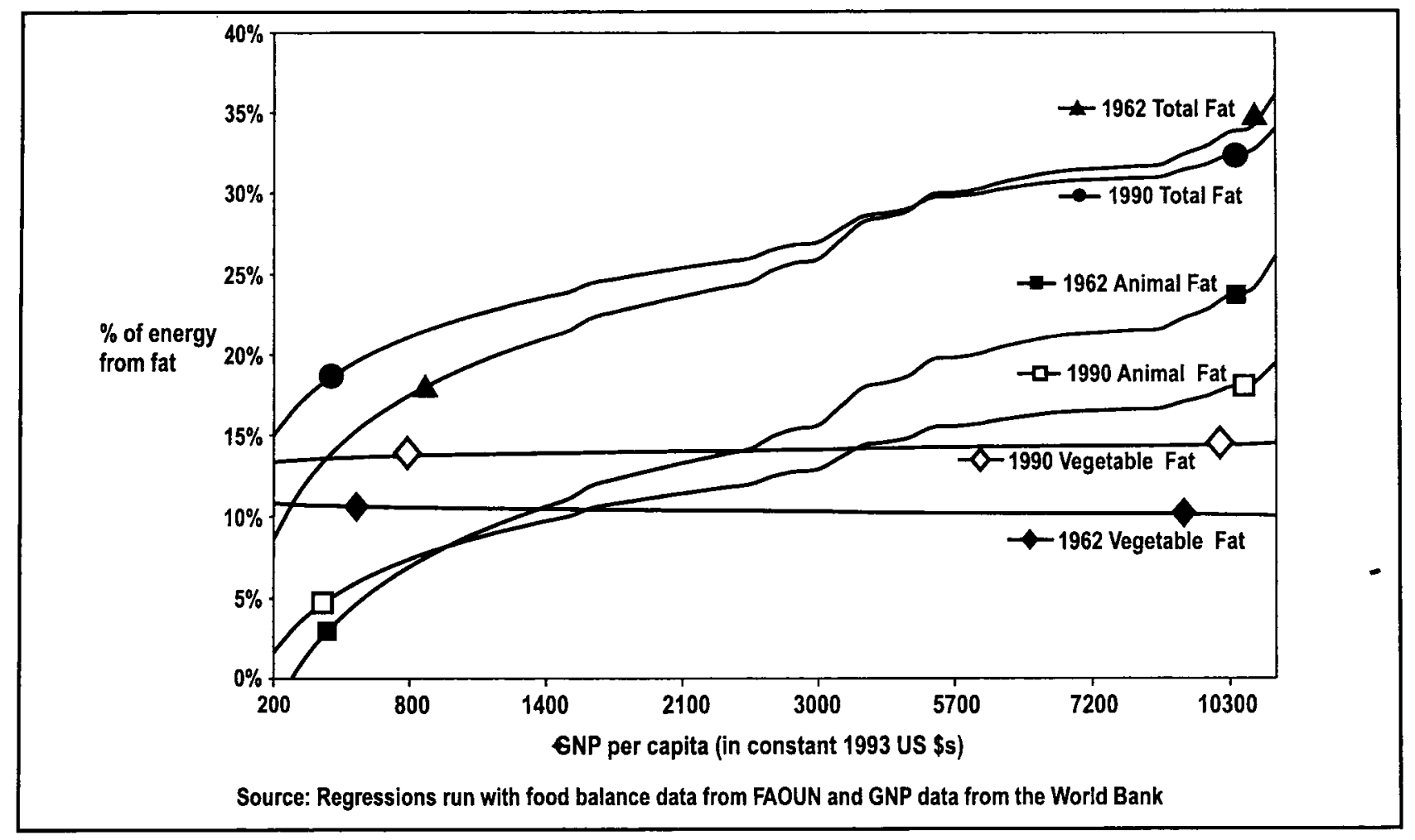

Figure 2. Relationship between the percentage of energy from fat and GNP per capita, 1962 and 1990.

the case and many lower-income countries now experience high rates of urbanization. ${ }^{20}$ In the regression analyses, the percentage of energy from each macronutrient was regressed on GNP per capita, the proportion of the population residing in urban areas that year, and an interaction term between GNP per capita and the proportion of urban residents. All variables in this regression were highly significant.

The income-diet relationship for the year 1962 is almost a direct replicate of the relationship established by Perisse et al..$^{3-4}$ except that our inclusion of the urbanization variable and the interactive term resulted in a less smooth transition. The availability of animal fats showed a marked linear relationship with income. Whereas the poorest nations derived as little as $5 \%$ of energy from animal fats, the richest nations derived as much as 38\% in 1962 . GNP levels had a significant, but less marked, influence on the percentage of energy from animal protein or from sweeteners. The proportion of vegetable fats in the diet was approximately constant at $8-10 \%$ energy, and was virtually independent of the GNP.

The data for 1990 found that the income-fat relationship underwent a dramatic change during the intervening three decades. The proportion of energy from vegetable fats in 1990 was much higher, accounting for up to $15 \%$ of total energy. The growing proportion of energy from animal fats was better described by a quadratic function, as richer nations consumed less but the poorest nations consumed more animal products and fats. As a result, total fat consumption was less dependent on the GNP than previously, resulting in a flatter curve. The relationship between incomes and energy from sweeteners and protein did not undergo major changes between 1962 and 1990 .

Most significantly, by 1990 even the poor nations had access to a relatively high-fat diet. Whereas in 1962 , a diet deriving $20 \%$ of energy from fat was associated with a GNP of $\$ 1,900$, the same diet was now associated with a GNP of only $\$ 900$ (both in 1993 dollars). This dramatic difference was largely accounted for by a major increase in the consumption of vegetable fats by poor and rich nations alike.

These trends in the income-fat relationship are documented further in regression analyses (without the urbanization variable) in Figure 2. GNP per capita is expressed in constant 1993 dollars. The data show that the percentage of energy from fat in 1990 was less dependent on income than previously. Although the availability of animal fats continued to be linked to income, but less strongly then before, vegetable fats now accounted for a greater proportion of dietary energy, and their availability was virtually independent of income. As a result of this adjustment, the lowest-income countries had access to an additional $4-5 \%$ of energy from fat. Although meat consumption declined in high-income countries (by 6-9\%), there was little overall reduction in fat intakes, as animal fats were replaced by a greater proportion of vegetable oils and products. The net result is a much lower, flatter curve representing the relationship between changes in GNP per capita and energy from all sources of fat. 


\section{Cheap Vegetable Fats}

Prosperity has always been associated with the consumption of a fat-rich diet. Historians have long used meat consumption as an index of prosperity of an era or of membership in a higher social class. ${ }^{21}$ Fat-rich diets have long been regarded as richer and more flavorful and often tend to be more varied for reasons discussed below. ${ }^{22}$ Until the decade following World War II, the majority of fats available for human consumption were animal fats, milk, butter, and meat.

The past five decades have seen a revolution in the production and processing of oilseed-based fats. Initially a rapid increase in the world demand for milk and meat products after World War II fostered the demand for protein supplements. Although the world need for protein received the most research and popular attention, growing availability of cheap fats may turn out to have had more impact on the human diet. Technological breakthroughs in the development of high-yield oilseeds and in the refining of high-quality vegetable oils greatly reduced the cost of baking and frying fats, margarine, butterlike spreads, and salad and cooking oils in relation to animal-based products. ${ }^{23}$ Worldwide demand for vegetable fats was fueled by health concerns regarding the consumption of animal fats and cholesterol. Furthermore, a number of major economic and political initiatives led to the development of oil crops not only in Europe and the United States but also in Southeast Asia (palm oils) and in Brazil and Argentina (soybean oils). The net effect was that from 1945 to1965, there was an almost fourfold increase in the U.S. production of vegetable oils, whereas animal fat production increased by only $11 \% .^{24}$

In the popular mind, the Westernization of the global diet continues to be associated with increased consumption of animal fats. Yet the nutrition transition in developing nations typically begins with major increases in the domestic production and imports of oilseeds and vegetable oils rather than increased imports of meat and milk. At this stage, vegetable oils contribute far more energy to the human food supply than do meat or animal fats. ${ }^{25}$ Between 1991 and 1996/7 global production of vegetable fats and oils rose from 60 million to 71 million metric tons. ${ }^{24}$ In contrast, the production of visible animal fats (butter and tallow) has remained steady at approximately 12 million metric tons. Principal vegetable oils include soybean, sunflower, rapeseed, palm, and peanut oils. With the exception of peanut oil, global availability of each has approximately tripled between 1961 and 1990. By the 1990s, soybean oil accounted for about $70 \%$ of the production and consumption of edible oils and fats in the United States, ${ }^{24}$ and soybeans now account for the bulk of vegetable oil consumption worldwide. The production and export of vegetable oils are promoted through direct subsidies, credit guarantees, food aid, and market development programs. ${ }^{25}$ According to U.S. Department of Agriculture data, the growth in demand for vegetable oils is strongest in the newly industrialized nations in East Asia. ${ }^{25}$

\section{Rapid Urbanization}

Analyses of links between economic factors and dietary trends have generally focused on the GNP as the key indicator of economic change. ${ }^{3,5}$ However, the potential role of urbanization should not be overlooked. Urbanization was included in our analyses because of the well-documented association of urban residence and diet structure. A large literature reviewed elsewhere ${ }^{16}$ shows that urban as opposed to rural diets are characterized by the consumption of superior and polished grains (rice or wheat, rather than corn or millet), more fats and animal products, more sugar, more processed foods, and more foods consumed away from home.

The potential impact of the urbanization variable on diet structure is shown by our regression model. The model used FAO food balance sheets and World Bank economic indicator data for 1990. The regression relating GNP per capita to the outcomes of energy from each food source includes as a covariate the proportion of residents residing in urban areas and an interaction between the proportion urban and GNP per capita. For purposes of clarification of the impact of shifts in urbanization, the results of those regressions were used to predict (simulate) the diet structure with the proportion of urban residents worldwide at either $25 \%$ or $75 \%$. Given rapid rates of urbanization in developing nations, this level of urbanization will be seen in most countries by the year $2020 .{ }^{20}$ As shown in Figures 3 and 4 , for higher rates of urbanization, the simulation developed from our model predicts a substantial increase in the consumption of sweeteners and fats. The clear implication is that a shift from $25 \%$ to $75 \%$ urban population in very low income countries would be associated with an added four percentage points of total energy from fat and an additional 12 percentage points energy from sweeteners.

This regression model predicts that rapid urbanization, usually associated with greater incomes and economic growth, can have independent effects on diet structure. At lower income levels, according to the regression model, urbanization can more than double the amount of sweeteners in the diet. The model confirms previous observations that people living in urban areas consume diets distinct from those of their rural counterparts. ${ }^{16,17}$ The potential impact of urbanization in flattening the income-sweetener relationship deserves further analysis; however, it is clear that the increased urbanization of lower-income nations is accelerating the shift to increased consumption of sweeteners and fats.

Analyzing the impact of urbanization on diet structure is a key issue for public health policy. ${ }^{17}$ Urbanization and economic growth, closely linked since the industrial revolution, give every sign of becoming dissociated. In the 


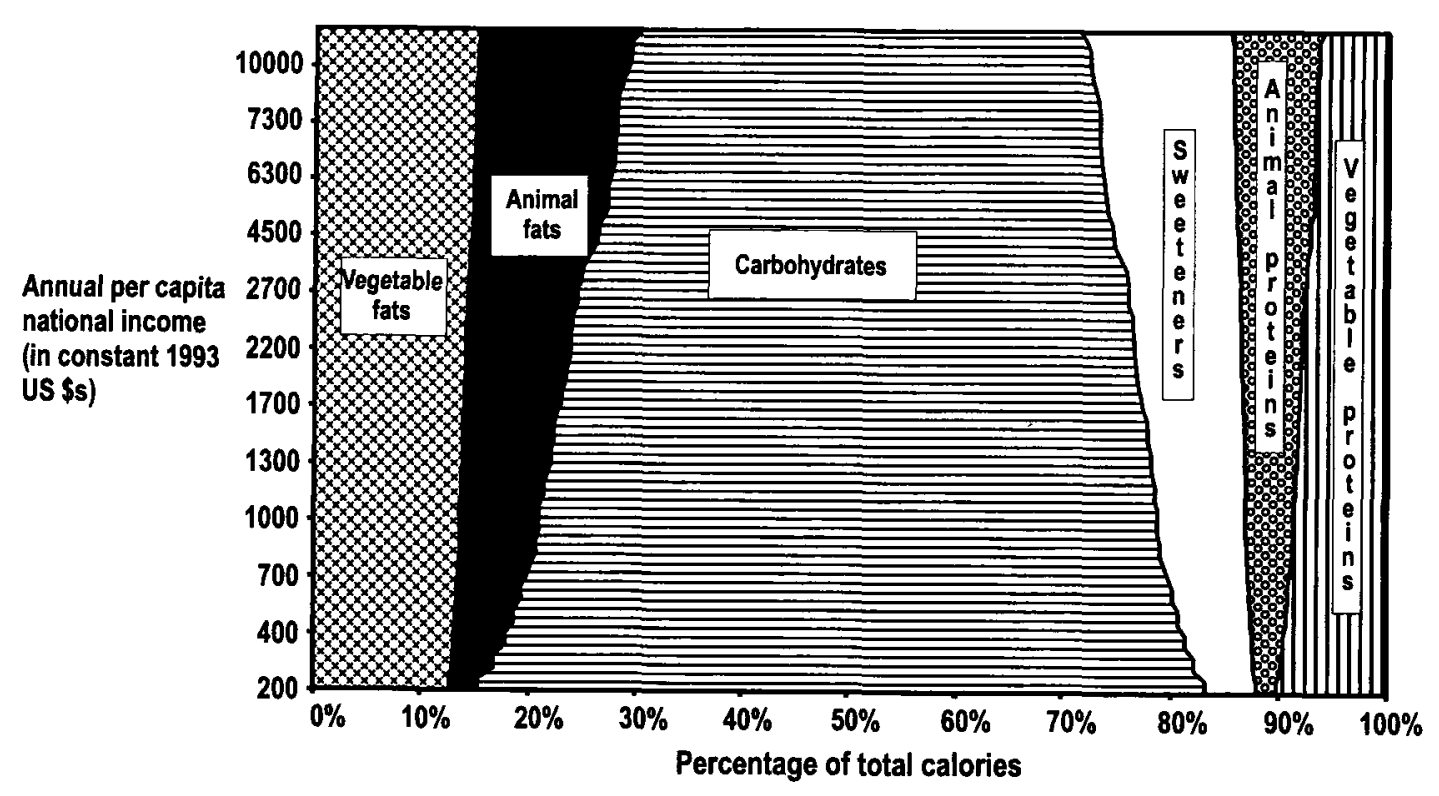

Source: Food balance data from the FAOUN; GNP data from the World Bank; regression work by UNC-CH

Figure 3. Relationship between the proportion of energy from each food source and GNP per capita with the proportion of the population residing in urban areas placed at $25 \%, 1990$.

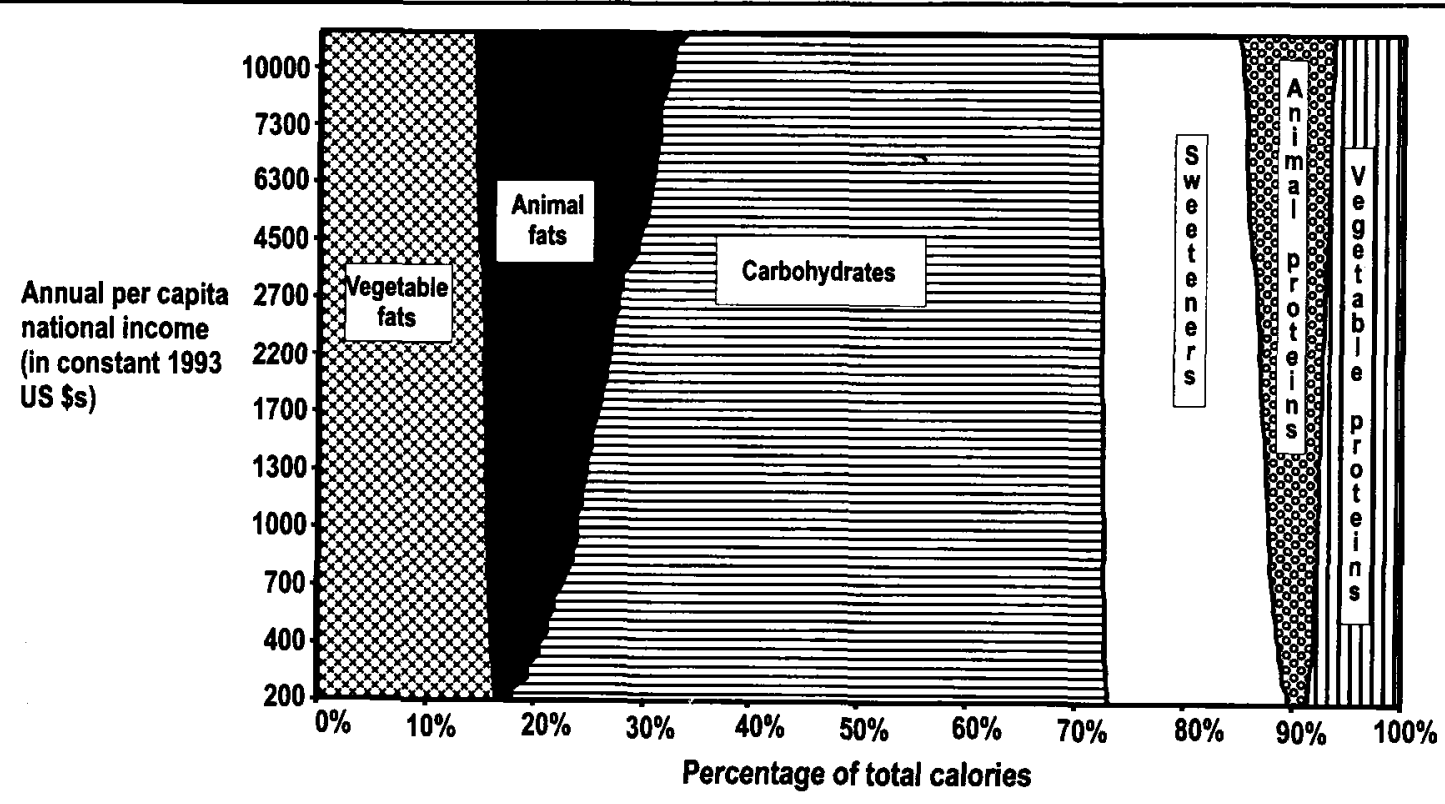

Source: Food balance data from the FAOUN; GNP data from the World Bank; regression work by UNC-CH

Figure 4. Relationship between the proportion of energy from each food source and GNP per capita with the proportion of the population residing in urban areas placed at 75\%, 1990.

past, rapid urban growth was concurrent with economic growth, whereas urban growth now dominates most lowincome countries (Table 1). In lower-income countries, this growth has been skewed toward a few larger cities, often called urban conglomerates. These cities of 5 million to 27 million dominate many countries and are growing much faster in the less-developed than in the more-developed regions of the world. The most explosive growth of these megacities is in Asia, where urban conglomerates with more than 8 million residents have grown annually from $2 \%$ in 1970 to a current estimate of $10 \%$ in 1994 to $19 \%$ in 2015.20

Urban agglomeration has been linked to the shift of poverty toward the urban areas, particularly toward squatter and slum areas. The rates of population growth are far greater in urban than in rural areas because of the continuation of long-term patterns of in-migration. These patterns are likely to accelerate in the next century as urban areas absorb the high rural unemployment and provide an in- 


\begin{tabular}{lccccccc}
\hline & \multicolumn{3}{c}{$\begin{array}{c}\text { Urban Population } \\
\text { (millions) }\end{array}$} & & \multicolumn{3}{c}{$\begin{array}{c}\text { Urban Share } \\
\text { (percentage) }\end{array}$} \\
\cline { 2 - 4 } \cline { 7 - 8 } Region & $\mathbf{1 9 7 0}$ & $\mathbf{1 9 9 4}$ & $\mathbf{2 0 2 5}$ & & $\mathbf{1 9 7 0}$ & $\mathbf{1 9 9 4}$ & $\mathbf{2 0 2 5}$ \\
\hline World & 1353 & 2521 & 5065 & & 36.6 & 44.8 & 61.1 \\
Less developed regions & 676 & 1653 & 4025 & & 25.1 & 37.0 & 57.0 \\
Least developed countries & 38 & 122 & 506 & & 12.6 & 21.9 & 43.5 \\
More developed regions & 677 & 868 & 1040 & & 67.5 & 74.7 & 84.0 \\
\hline
\end{tabular}

Source: United Nations: Population Division, 1995.

creasing proportion of market employment in all countries in the world. The prediction is that urban residency will be the norm by 2025 for all but the poorest African countries. Its consequences on diet and disease are likely to be profound. ${ }^{17}$

\section{Emerging Trends in Asia}

The impact of economic factors on the nutrition transition has been particularly apparent in Asian nations. Economic growth in some parts of Asia has been extremely rapid, so that developed and developing nations can be found in the same geographic region. Such regions have typically shared a common diet structure, and traditional Asian diets invariably have been described as high in carbohydrates and low in fat. ${ }^{26}$ However, it is generally acknowledged that this pattern is undergoing a profound change. . $7-30^{27}$

Analyses of food available for consumption and GNP data for 21 Asian nations during 1975-1994 show an overall decline in the proportion of energy from complex carbohydrates and a corresponding increase in the proportion of energy from total fats. Countries were categorized by GNP in 1994. As expected, diet structure was strongly dependent on income levels. The 10 low-income countries with 1994 per capita GNP in the $\$ 190-\$ 880$ range included Cambodia, China, India, Myanmar, and Vietnam. The six middle-income countries with GNPs in the range $\$ 1,000$ $\$ 8,000$ included Malaysia and Thailand. High-income Asian countries included Taiwan, Hong Kong, and Japan. These data are summarized in Figure 5, with U.S. data included for comparison purposes.

As shown in Figure 5, changes in diet structure occurred as a function of time. As economies and GNP grew between 1975 and 1994, so did the proportion of energy from fats. The same trend was observed for countries at all levels of income. Interestingly, the global trend seems to be toward a diet deriving $30-35 \%$ of energy from fat. The pattern of the relationship between energy and fat is not significantly different in these three sets of countries.

\section{Incomes and the Structure of Diet in China}

Similar relationships between incomes and diet structure can also be demonstrated at the individual level within a given nation. China, the fastest-growing world economy, is still in the relatively early stages of the nutrition transition. The nutrition transition in China has been associated with rapid urbanization, a decrease in fertility, a decline in mortality, and an increase in education and affluence. ${ }^{31,32}$

We can predict, based on our analyses of FAO food balance data, that emerging economies such as China will experience the nutrition transition much sooner and at a much lower level of GNP than might have been expected from the earlier experience of the United States and Western European societies. Data from the China Health and Nutrition Survey (CHNS) for 1989 and 1993 provide additional evidence regarding incomes and fat consumption at the individual level at two points in time (see Popkin et al. ${ }^{30}$ for information on this survey).

Dietary change in China has been extremely rapid. Over the last decade, China has attained a high measure of food security and has seen marked changes in the adequacy and the structure of the diet. ${ }^{31,32}$ The traditional Chinese diet was generally assumed to be low in fat, ${ }^{26}$ which may haye been a reflection of poverty rather than concerns with nutrition and health. As incomes rose, carbohydratebased diets were gradually abandoned. As shown in Figure 6 , respondents in the lowest tertile by income were most likely to consume a diet with less than $10 \%$ of energy from fat both in 1989 and in 1993. The proportion of respondents consuming a low-fat diet declined significantly between 1989 and 1993 for all income tertiles. Conversely, upper-income respondents were more likely to consume a diet deriving more than $30 \%$ of energy from fat (see Figure 7). By 1993, higher-income urban populations were far more likely to consume a diet with $30 \%$ fat than were rural and lower-income populations. The proportion of upper-income respondents who were consuming a relatively high-fat diet rose from $22 \%$ to $66 \%$ between 1989 and 1993 .

These data confirm that a highly positive income elasticity between income and fat consumption still exists within China for a wide range of incomes. Similar income gradients have been shown to exist in Brazil. ${ }^{33}$

Based on our global analyses (see above), we might expect that the early stages of the nutrition transition in China would be accounted for by sharply increased availability of vegetable fats. Indeed, USDA estimates ${ }^{34}$ show that China's production of oilseeds increased by $50 \%$ between 1991 and 1996. At the same time, imports of all vegetable oils more than tripled, and imports of soybean oil alone increased by 15 times $(0.1$ million to 1.5 million metric tons). However, China's oil imports are slowing down, perhaps in response to increased domestic production and 


\section{Complex \\ Carbohydrate}

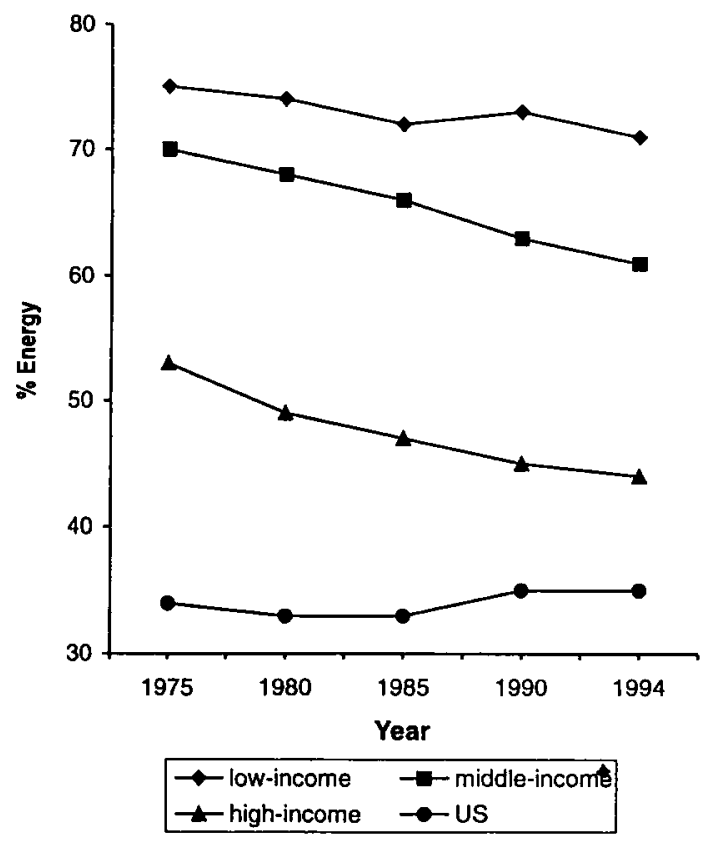

Fat

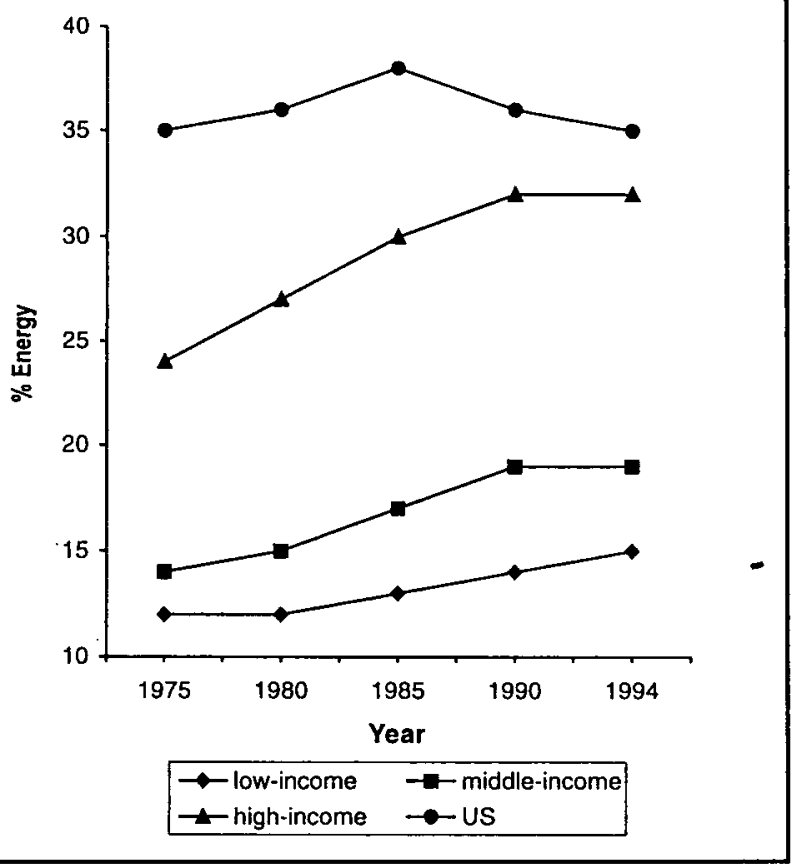

Figure 5. The relationship among availability of carbohydrates, fat, and GNP in Asia.

anticipated greater consumption of meat.

\section{Dietary Diversity}

Some nutritionists in developing nations have been at a loss to explain why their traditional staples and side dishes are being abandoned in favor of diets containing a higher proportion of sugars and vegetable or animal fats. ${ }^{10-11} \mathrm{Re}-$ lated is the high "time intensity" of these staple dishes. Concomitant with the increase in diversity is the selection of foods that require less time and skill to prepare and consume ${ }^{35}$ One explanation may be that a critical component of the nutrition transition is a more diverse and varied diet. Despite a certain nostalgia for the reputed health effects of diets of poverty, ${ }^{26,36}$ the unshakable fact is that diets of poor societies are based on a very limited number of foods, and often consist of little more than starchy roots and coarse grains. Although low in fat and high in fiber, these foods offer little in the way of diversity or variety, essential components of eating pleasure. The nutrition transition typically involves a shift from a limited number of high-carbohydrate staples to a more diverse diet that becomes available to progressively more people.

As incomes grow, diets become more diverse and more people incorporate meat and fish, milk, eggs, and cheese, as well as vegetables and fresh fruit, into their habitual diets. Insofar as new foods are being introduced into the diet, they invariably include meat, eggs, and sweets previously inaccessible to most low-income people. Some of these new foods are high in fats, simple sugars, or both.
As a result, dietary diversity and the proportion of fats in the diet are sometimes directly linked.

Analyses of the Chinese diet, assessed by the 1989 CHNS survey, ${ }^{30}$ show that diets of the poor were largely based on rice, millet, sorghum, cabbage, salted vegetables, soybean sauce, and salt, with some meat (pork). Higherincome respondents replaced coarse grains and starchy tubers with more rice and wheat. As incomes rose, vegetables and pickled vegetables were replaced with more meat, poultry, eggs, dairy products, and fresh fruit. As more different foods were consumed, portion sizes (in grams/day/user) generally dropped for all foods, except meat, fresh fruit, and alcohol.

Our analyses of dietary diversity in China are summarized in Table 2. First, all foods consumed were aggregated into 18 foods and food groups, so that the maximum diversity score was 18 . Among the groups were rice, wheat flour, other grains, meat, poultry, fish, vegetable oils, animal fats, sweets, vegetables, fruit, and alcohol. The data show that the mean dietary diversity score increased sharply with income tertiles. More important, the proportion of the population consuming only five of the 18 food groups dropped sharply with increases in income, whereas the proportion of the population consuming nine of 18 foods, on the contrary, increased.

Dietary diversity at all income levels increased between 1989 and 1993, reflecting an improvement in dietary adequacy nationwide. These data are compatible with the trends for fat consumption in China (Figures 4 and 5). The 


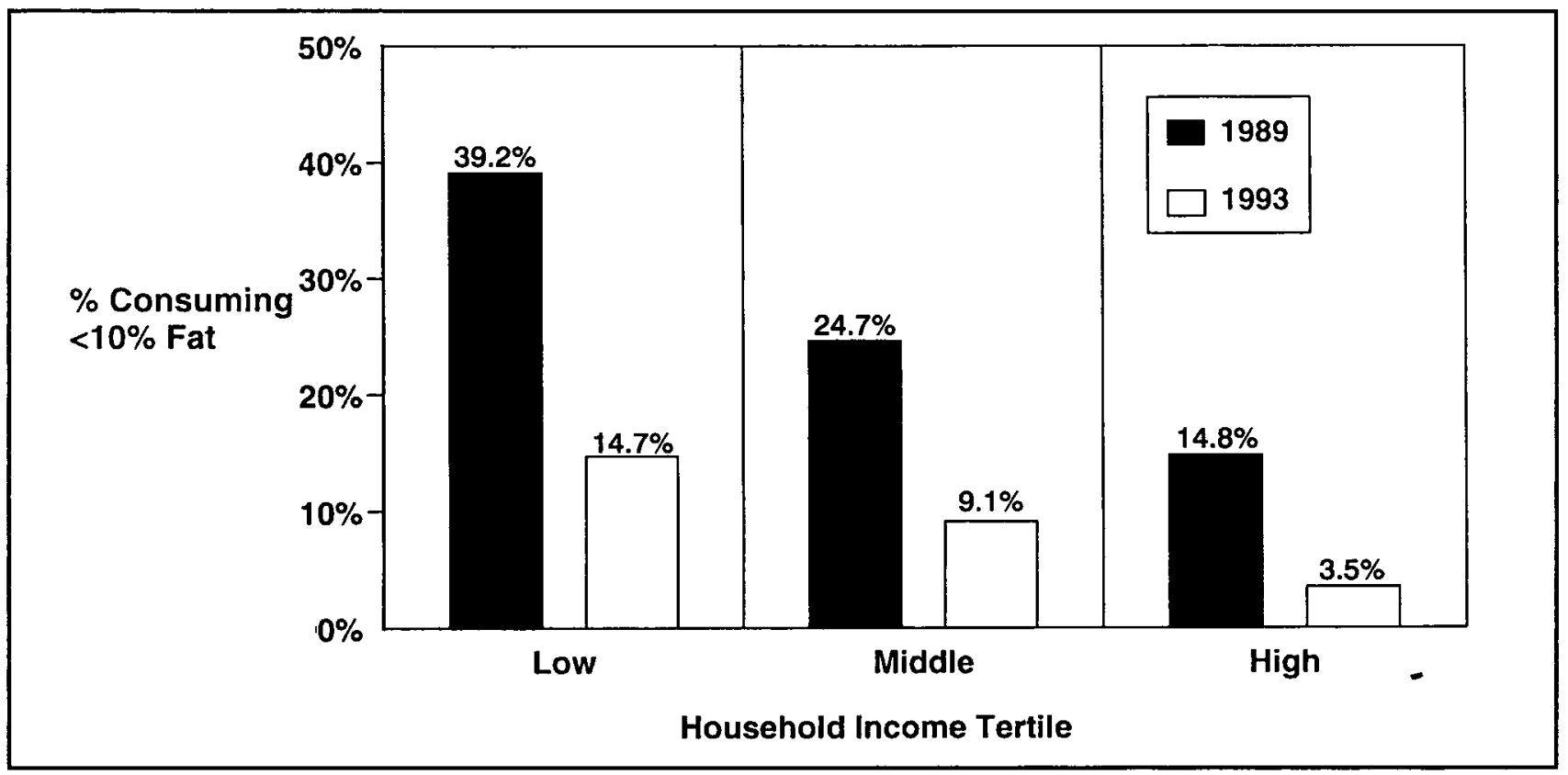

Figure 6. Relationship among the proportion of the population consuming a low-fat diet (\% energy from fat below 10), income, and urban residence, China Health and Nutrition Survey.

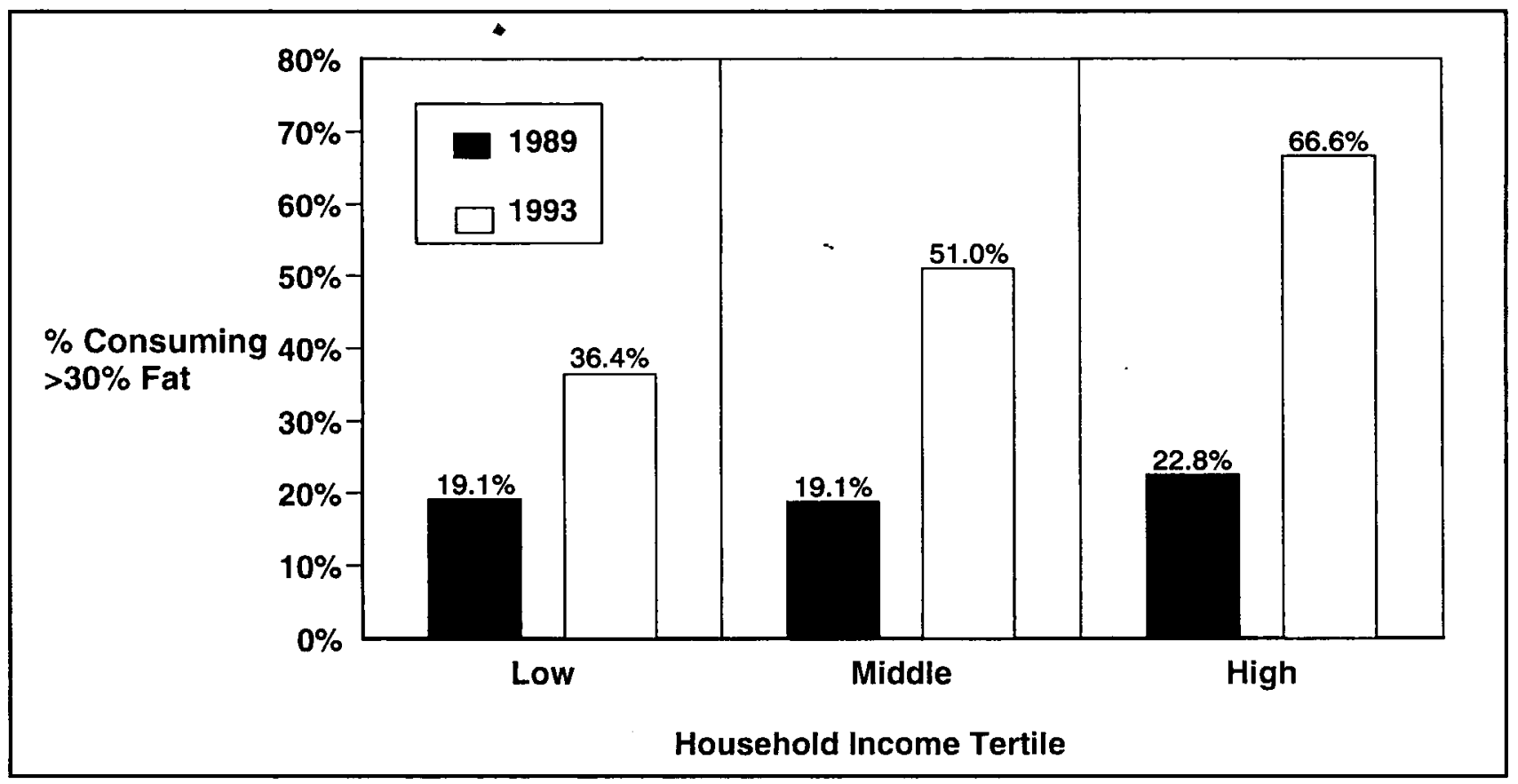

Figure 7. Relationship among the proportion of the population consuming a high-fat diet $(\%$ energy from fat above 30 , income, and urban residence, China Health and Nutrition Survey.

higher proportion of fats and sugar in the Chinese diet at this early stage of the nutrition transition may simply reflect improved diversity and variety of the food supply. Although some observers ${ }^{26}$ have noted a substantial preference for foods of plant origin in the Chinese diet, it appears that this high-plant-food dietary pattern reflects poverty rather than preferences. Arguably, then, greater dietary diversity, not necessarily the desire for sugar and fat per se, might be at the core of the nutrition transition.

\section{The NutritionTransition in Japan}

Japan provides an example of late stages of the nutrition transition. Japan went through a process of accelerated economic growth from 1950 to 1970 , and its 1994 GNP exceeded that of the United States. The question is whether Japan can serve as a model for China and whether the same stages of the nutrition transition will be followed in a predictable sequence in China.

There is no question that the Japanese diet is richer in 
Table 2. Diversity in the Chinese Diet: the Number of Food Groups Consumed by Chinese Adults, Aged 20-45Years, CHNS 1989

\begin{tabular}{clcccc}
\hline & & \multicolumn{3}{c}{ Income Tertiles } & \\
\cline { 3 - 5 } Year & & Low & Medium & High & Total \\
\hline 1989 & $n=$ & 1950 & 1950 & 1881 & 5781 \\
& Mean score & 5.4 & 6.5 & 7.4 & 6.4 \\
& Score $<4 \%$ (\%) & 32.5 & 14.3 & 7.4 & 18.2 \\
& Score > 8(\%) & 1.9 & 6.8 & 17.1 & 8.5 \\
1991 & $n=$ & 1886 & 1944 & 1864 & 5694 \\
& Mean score & 5.9 & 6.9 & 7.9 & 6.9 \\
& Score <4 (\%) & 24.0 & 10.8 & 4.7 & 13.2 \\
& Score > 8(\%) & 3.2 & 9.8 & 19.6 & 10.9 \\
1993 & $n=$ & 1759 & 1824 & 1689 & 5272 \\
& Mean score & 6.0 & 7.0 & 7.8 & 6.9 \\
& Score <4 (\%) & 19.2 & 10.7 & 4.1 & 11.4 \\
& Score >8(\%) & 4.5 & 12.4 & 19.2 & 12.0 \\
\hline
\end{tabular}

Note: The range of diversity scores is $1-18$.

fats and sugars than ever before. ${ }^{27,37}$ Western observers less often appreciate that it has also become more diverse. In 1910 the daily per capita intake in Japan consisted of 430 $\mathrm{g}$ of carbohydrate (rice and beans), $13 \mathrm{~g}$ of fat, andonly $3 \mathrm{~g}$ of animal protein. In 1989, daily intake of carbohydrate dropped to $190 \mathrm{~g}$, but fat intake rose to $59 \mathrm{~g}$ and animal protein intake rose to $42 \mathrm{~g} /$ day. At the same time, the consumption of salt, the principal condiment for bland rice, dropped from an estimated $30 \mathrm{~g} /$ day to $12 \mathrm{~g} /$ day.

During that time, traditional eating habits-a diet of rice (with salt) accompanied by soybean soup and pickled vegetables with some fish and shellfish-have been replaced by what the Ministry of Agriculture, Forestry and Fisheries (MAFF)" calls the "new Japanese type eating habits." These are small servings of boiled rice, with the addition of meat, fish, vegetables, and milk. The Japanese diet now includes red meat, poultry, milk and other dairy products, eggs, fruit, and fresh vegetables, all of which had been inaccessible to the average consumer. $\mathrm{MAFF}^{29}$ specifically credits the economic revolution and the provision of lunch to schoolchildren for these improvements in Japanese eating habits.

Although fat consumption in Japan almost tripled between 1946 and 1987 (from 9\% to $25 \%$ of daily energy), fat content of the diet is not the only criterion for diet quality (Table 3). As recently as 1955, the Japanese diet was based on cereals ( $66 \%$ of daily energy), predominantly rice. This has now declined to $39 \%$. In contrast, there were major increases in meat consumption ( 7.3 to 63.1 pounds), a huge increase in chicken consumption (35-fold), and a major increase in the consumption of milk (sixfold) and eggs (fivefold). Although fish consumption is high, there has been a shift from cheap sardines, mackerel, and herring to more expensive salmon, tuna, shrimp, and lobster. The consumption of vegetable fats and oils increased from 6 to 31.5 pounds. Fruit and vegetable consumption increased up to 1970 but is now stagnant. Most of the transition was accomplished through growth in domestic production rather than food imports. Significantly, Japan no longer imports cheap vegetable oils, but does import significant amounts of meat and poultry.

Western observers commenting on Japanese eating habits have almost invariably focused on the health risks of growing fat consumption. " However, not all Japanese nutrition experts have shared this view. Although it is generally acknowledged that Western habits have penetrated Japanese life to an enormous extent, bringing important changes in dietary and eating practices,$^{38}$ these changes are generally viewed as beneficial. Some nutritionists ${ }^{39}$ have remarked on the benefits of a mixed diet and its excellently balanced ratio of animal to vegetable protein. Others have noted, rather more pointedly, that the increased intakes of animal foods, such as meat, eggs, milk, and dairy products, have greatly improved the nutritional status of the Japanese people. ${ }^{38}$

\section{Human Preferences for Sugar and Fat}

Preferences for dietary sugars and fats are regarded by many as an innate human trait. Sweetness, in particular, serves as the major cue for food energy in infancy and childhood, and preferences for sweet taste are observed in all societies around the globe. ${ }^{40} \mathrm{An}$ argument has been made that preferences for dietary fats are also either innate or learned in infancy of childhood. ${ }^{41}$ References to the desirable qualities of milk and honey (i.e., fat and sugar), cream, butter, and animal fats are found throughout recorded history. All human societies, whatever their income, prize foods containing sugar and fat the most. ${ }^{21}$

The role of dietary sugar and fat in weight control has become an issue in obesity research. ${ }^{22,42,43}$ Some researchers have proposed that the selection of dietary macronutrients is governed by physiologic or metabolic events. ${ }^{44}$ In their view, the selection of fat-rich as opposed to carbohydrate-rich foods is primarily determined by brain mechanisms that may include central levels of neurotransmitters, hormones, or neuropeptides. Other models of nutrient selection have invoked central levels of the neurotransmitter serotonin or the endogenous opiate peptide system. ${ }^{45,46}$ Recent studies on the genetics of obesity have pointed to the importance of leptin, a protein, in the control of food intake and the development of obesity in rats and mice. ${ }^{47}$ In this view, human obesity represents a chronic metabolic disease that is best treated by pharmacological intervention.

A related view is that obesity represents the combined outcome of a genetic predisposition and prolonged exposure to an energy dense diet. What is inherited is not obesity per se, but a vulnerability to the fattening effects of certain foods. Researchers have variously explored the effects of energy intake and expenditure and the relative contributions of diet and exercise to weight control. ${ }^{48,49}$ The current consensus is that growing inactivity, another consequence of a shift from rural to urban centers, greatly 
Table 3. Changing Diets in Japan, 1955-1994 (kg/capita/year)

\begin{tabular}{lrrrrrrrr}
\hline Item & $\mathbf{1 9 5 5}$ & $\mathbf{1 9 7 0}$ & $\mathbf{1 9 7 5}$ & $\mathbf{1 9 8 0}$ & $\mathbf{1 9 8 5}$ & $\mathbf{1 9 9 0}$ & $\mathbf{1 9 9 3}$ & $\mathbf{1 9 9 4}$ \\
\hline Cereals & 156.1 & 128.5 & 121.5 & 112.9 & 107.9 & 103.5 & 103.0 & 100.9 \\
Meats & 3.3 & 13.4 & 17.9 & 22.5 & 25.1 & 28.5 & 29.9 & 30.6 \\
Fish and shellfish & 26.4 & 31.7 & 34.9 & 34.8 & 35.8 & 37.1 & 36.7 & 36.1 \\
Eggs & 3.4 & 14.8 & 13.7 & 14.3 & 14.9 & 16.5 & 17.9 & 17.8 \\
Milk and dairy & 12.1 & 50.2 & 53.6 & 65.3 & 70.6 & 83.2 & 83.6 & 89.2 \\
Fruit & 12.3 & 37.7 & 42.5 & 38.8 & 36.8 & 37.4 & 39.3 & 42.8 \\
Vegetables & 82.6 & 115.9 & 109.4 & 112.0 & 110.2 & 107.2 & 102.6 & 102.9 \\
Potatoes & 46.2 & 16.1 & 16.0 & 17.3 & 18.6 & 20.6 & 19.8 & 20.4 \\
Sugars & 12.3 & 27.0 & 25.1 & 23.3 & 21.7 & 21.0 & 19.3 & 19.7 \\
Fats and oils & 2.7 & 9.0 & 10.9 & 12.6 & 14.0 & 14.2 & 14.4 & 14.4 \\
\hline
\end{tabular}

Source: Japan, Ministry of Agriculture, Forestry and Fisheries, 1990-1991 and 1996.

contributes to the rising rates of obesity worldwide.

There is little evidence that food choices are governed by regulatory mechanisms that favor macronutrient selection. Rather, according to sensory studies, the sense of taste acts as the gatekeeper for food consumption. ${ }^{49}$ In particular, preferences for sweet taste are the chief sensory cue for food energy. Whereas children like intensely sweet foods and do not show the usual sucrose "breakpoint," adults with lower energy needs find some foods too intensely sweet and therefore unpleasant. As a result, sugar intakes decline sharply between childhood and adult life, and added sugars contribute a lower proportion of energy to the adult diet. ${ }^{40}$ In contrast, no comparable regulatory system has been found for dietary fats. Given that sensory perception of fats in foods is often inaccurate, some researchers have referred to fats as "invisible calories." Others have proposed that regulatory mechanisms for fat intake are lacking and that passive overconsumption of fats can lead to excessive energy intake and therefore obesity. ${ }^{45}$

Studies of internal regulation of macronutrient preference are in basic conflict with observations that consumption of fats is influenced primarily by economic variables. However, many scientists have come to believe that physiologic mechanisms that regulate fat intake are so imprecise that fat consumption is largely determined by the amount of fat available in the food supply. ${ }^{49}$ In contrast, the proportion of protein in the diet is largely independent of income and appears to be regulated by some internal physiologic mechanism. Another way to view the trend toward higher fat is the desire for a more diverse diet. Diets that incorporate meat and dairy products in addition to vegetables and grains tend to be higher in sugar and fat.

\section{The Impact on Child Health}

Concurrent with these changes in diet structure are equally dramatic shifts in activity and body composition patterns among all age groups. A major reduction in undernutrition in developing countries has been accompanied by a surprisingly rapid rise in obesity, particularly childhood obesity. ${ }^{8}$ Even in societies that had few persons who would be termed obese or overweight a decade ago, child and adult obesity are becoming public health problems. Indeed, rates of childhood obesity in emerging economies are rising so rapidly that they will soon reach the levels of childhood obesity in the United States-levels that have been called epidemic by physicians and public health experts. ${ }^{8,50}$

Growing rates of obesity in low- and middle-income countries are still positively linked with higher household incomes. However, there are already instances in Latin America and in Caribbean countries where the poor are more likely to be obese than the rich. ${ }^{1}$ This is already the case in Brazil, Chile, and other countries in Latin America. ${ }^{51}$ We predict that this inverse relationship between obesity and income will be found in more countries within a decade, particularly in countries characterized by large agglomerates of urban poor. The narrowing gap in the rates of.childhood obesity between the United States and China, a country with no reported child obesity a generation ago, is indicative of a pattern of change that one will find in many countries in Southeast Asia.

Estimated rates of childhood obesity for selected countries are summarized in Figure 8. Data for the United States based on body mass index (BMI) for children 6-8 years old in the NHANES III data set (1989-1991) are compared with the nationally representative surveys for Russia, South Africa, and Brazil and the nationwide survey from China. ${ }^{8}$ In all cases, the definition of obesity was based on the 95 th percentile BMI cut point for sex and age - the most extreme definition of obesity used by the National Center for Health Statistics. ${ }^{52}$ Although the prevalence of childhood obesity in the United States was still the highest, trends among low-income countries were beginning to approach that level.

\section{Discussion: Globalization of the Human Diet}

World economic development has been associated with both an improvement and a progressive globalization of the human diet. As the world economy grows, differences in the structure of diet between nations at different levels of income are becoming less marked. Among the emerging trends in the global diet are a greater dietary diversity and an increased proportion of vegetable fats and, to a lesser extent, sugars. The globalization of the human diet appears to be the combined outcome of innate sensory preferences coupled with the greater availability of cheap fats 


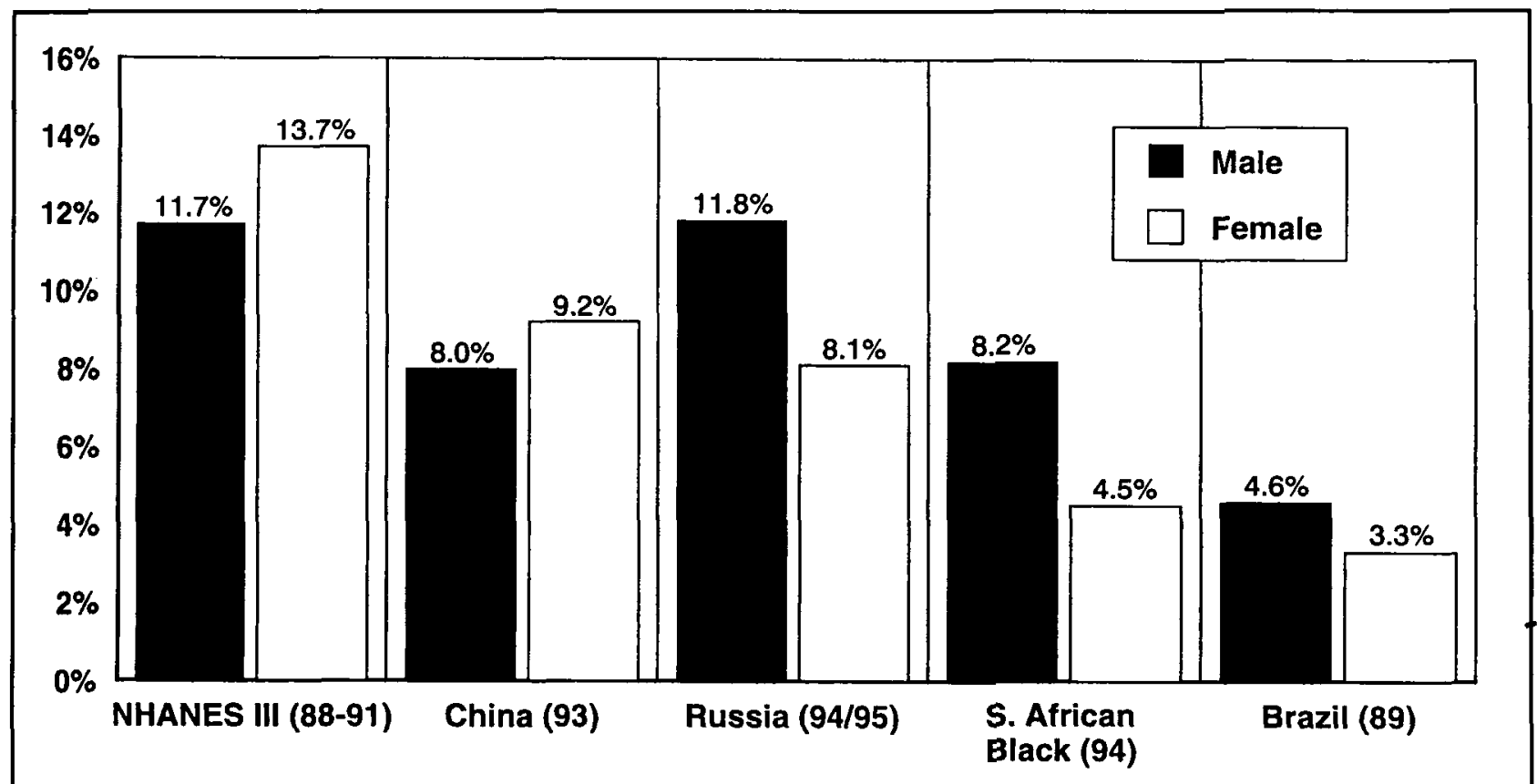

Note: $6-8$ years is equivalent to $72-108$ months

Figure 8. Prevalence of obesity among 6-8-year-old children: comparison with the U.S. 95 th centile.

in the global economy and rapid social changes in the lower-income world.

We have new evidence that the centuries-old relationship between the income levels of nations and their level of fat consumption has undergone a fundamental change. Whereas rich societies used to consume fat mostly in the form of meat and milk products, lower-income countries consumed very little fat until improvement in income permitted access to a higher-fat diet. The recent availability of cheap vegetable oils has made high-fat diets accessible even to low-income societies. At present, the income elasticity for fat at the macroeconomic level is much lower than previously, and vegetable fats account for an ever-increasing proportion of energy in the global diet. Even though high-income nations have cut back on meat consumption, perhaps in response to nutrition policies and programs, the total amount of fat in the diet remains largely stable as vegetable oils substitute for animal fats.

Social and demographic factors play an important role. In particular, growing urbanization has had a major impact on diet structure that is independent of income. Whereas in the past, increases in GNP and urbanization were tightly linked, the pace of urbanization in many lower-income nations has exceeded economic growth. The present regressions and resultant simulations suggest that increased urbanization may be associated with greatly increased consumption of both sweeteners and vegetable fats. The impact of reduced physical activity in urban as opposed to rural societies is another contributing factor that deserves additional study.

The loosening of the relationship between GNP and fat intake at the macro level does not mean that within- country differences in income have no impact on diets. On the contrary, higher individual incomes in lower-income societies are invariably associated with greater consumption of dietary fats, as demonstrated above in the case of China. This pattern contrasts with the United States, where the relationship between socioeconomic status and fat intake is inverse, ${ }^{8}$ as is the relationship between socioeconomic status and overweight.

The present analyses point to a global convergence toward a diet deriving a higher proportion of energy from fat. That diet more closely approximates the diets of the United States and Western Europe than any traditional diet of Asia or Africa. Why this occurs is only open to conjecture. The desire for dietary variety and the associated sensory preferences for sugar and fat appear to be an innate human trait. The current consensus is that fat consumption is not regulated by any physiologic mechanism and, instead, may simply depend on preferences for fat and its availability in the food supply. Dietary variety is an important and as yet unacknowledged factor, as diets richer in fat also tend to be more varied.

Consumers in emerging economies may be unwilling to return to diets of poverty once a certain level of income has been achieved. As the nutrition transition proceeds, diets typically become more diverse, with the traditional root vegetables and coarse grains replaced by rice and wheat, which are in turn supplemented or replaced by meat and milk products, fresh vegetables, and fruit. Diets based on a broader range of food groups generally contain an increased proportion of dietary fats and sweeteners. This process, which has occurred in much the same form throughout human history, is now observed in Asia in a 
greatly accelerated form.

The globalization of the human diet does not appear to be driven at this point by meat imports, fast foods, or eating away from home, at least in the Asian countries studied in depth. Many in the West have claimed that the culture of sweet and high-fat foods - a culture associated with increased availability of fast foods in markets and restaurants-has been driving the global increase in fat consumption. Analyses of food import data for lower-income countries do not back up this claim. The nutrition transition in China has been based until now on greatly increased domestic production and imports of vegetable oils, and not on imports of Western foods and a Western way of eating. At this time, food consumption away from home as well as sugar intakes in China represent a minuscule portion of dietary energy. ${ }^{53}$ The late stages of the nutrition transition in Japan are characterized by greater consumption and import of meat and milk products and increased imports of processed foods.

There is a strong likelihood that a diet containing approximately $30 \%$ of energy from fat will become or has become the global norm. Thus far, nutrition experts have used the proportion of fats in the diet as the sole measure of diet quality, ${ }^{7}$ and high-fat diets are generally regarded as unhealthy. However, for many lower-income nations, diets higher in fats and sweeteners are also more varied and include a higher proportion of high-quality animal protein. Diet quality needs to be assessed using more complex tools, and new measures of the "total" diet and healthy eating habits have began to focus on the relative contributions of dietary balance, moderation, and variety. ${ }^{49,54,55}$ Fat has a place in the total diet, and the lowest fat diets are not necessarily the most healthy.

One issue that must be addressed is the potential irreversibility of emerging dietary trends. The nutrition transition has been associated with greater dietary variety and increased consumption of dietary sugars and fats. According to United Nations data, ${ }^{56}$ these trends are not reversed by a transient economic downturn. Given that growing consumption of dietary fats is unlikely to be limited by physiologic constraints, one strategy for modifying diet structure might be through appropriate nutrition policies and programs.

It is not too soon for developing nations to develop policies for education and intervention that would avert some of the adverse health effects of the nutrition transition. While preserving dietary diversity, such policies would steer the population toward a more healthful diet. It is not clear whether the relationship between changing incomes and diet can be reversed or slowed down through nutrition education and intervention strategies, and whether this can occur at low levels of fat consumption. Data from the United States and some Scandinavian countries suggest that some success may be achieved at keeping the fat content of the diet at around $30 \%$. In the Scandinavian coun- tries, in particular, aggressive state policies related to taxation and import tariffs, as well as consumer education, are believed to have made an impact on both dietary choices and public health. ${ }^{12,57}$ The present findings have major implications for the design of nutrition education and nutrition intervention programs worldwide. In particular, these results point to the need for active public policy to promote a healthy diet.

Acknowledgments. Preparation of this article was supported in part by grants from the U.S. National Institutes of Health (P01HD28076-01). The authors thank Elena Glinskaya and Xuguang Guo for their exceptional research assistance in the preparation of the data set, Tom Swasey and Nicholas Drzal for their work on the graphics, Lynn Igoe for editorial assistance, and Frances Dancy for administrative assistance. They also credit collaborators on the China Health and Nutrition Survey, in particular Drs. Ge Keyou and Zhai Fengying, Institute of Nutrition and Food Hygiene, Chinese Academy of Preventive Medicine.

1. Popkin BM. The nutrition transition in low-income countries: an emerging crisis. Nutr Rev 1994;52:285-98

2. World Bank. World development report 1993. Investing in health: world development indicators. New York: Oxford University Press for World Bank, 1993

3. Perisse J, Sizaret F, Francois P. The effect of income and the structure of the diet. FAO Nutr Newslett $1969 ; 7: 1-9$

4. Food and Agriculture Organization of the United $\mathrm{Na}$ tions. Income effect on the structure of diet: provisional indicative world plan for agricultural development. Rome: FAO, 1970;2:500-5

5. Chevassus-Agnes S. Disponibilités des lipides alimentaires dans le monde. Food Nutr Agr 1994;11:15-22

6. Omran AR. The epidemiologic transition: a theory of the epidemiology of population change. Milbank Mem Fund Q 1971;49(4, pt. 1):509-38

7. Posner BM, Franz M, Quatromoni P, et al. Nutrition and the global risk for chronic disease: the INTERHEALTH nutrition initiative. Nutr Rev 1994:52:201-7

8. Popkin BM, Richards MK, Monteiro CA. Stunting is associated with overweight in children of four nations that are undergoing the nutrition transition. $J$ Nutr 1996a;126:3009-16

9. O'Dea K. Westernization and non-insulin-dependent diabetes in Australian Aborigines. Ethnicity Dis 1991;171-87

10. Gopalan C. Nutrition in developmental transition in South-East Asia. SEARO Regional Health Paper 21. New Delhi: World Health Organization, 1992

11. World Health Organization. Diet, nutrition, and the prevention of chronic diseases: report of a WHO study group. WHO Technical Report Series No 797. Geneva: WHO, 1990;1-203

12. Milio N. Nutrition policy for food-rich countries: a strategic analysis. Baltimore: Johns Hopkins University Press, 1990

13. U.S. Department of Agriculture. USDA's food guide pyramid. Home and Garden Bulletin No 249. U.S. Departments of Agriculture and Health and Human 
Services. Hyattsville, MD: USDA, 1992

14. U.S. Department of Agriculture. Nutrition and your health: dietary guidelines for Americans, 4th ed. Home and Garden Bulletin no. 232. U.S. Department of Health and Human Services. Hyattsville, MD: USDA, 1995

15. Popkin BM, Siega-Riz AM, Haines PS. A comparison of dietary trends among racial and socioeconomic groups in the United States. New Engl J Med 1996b;335:716-20

16. Popkin BM, Bisgrove E. Urbanization and nutrition in low-income countries. Food Nutr Bull 1988;10(1):3 23

17. Solomons NW, Rainer G. Urban nutrition in developing countries. Nutr Rev 1995;53:90-5

18. Food and Agriculture Organization of the United Nations/FAOSTAT.PC. Food balance sheets 1961-94. Rome: FAO

19. World Bank. World data 1995 [CD-ROM]. Washington, DC: World Bank, 1995

20. United Nations DELSA. World urbanization prospects: the 1994 revisions. ST/ESA/SERA/150. New York:UN, 1995

21. Fischler C. L'Homnivore: le gôvt, la cuisine et le corps. Paris: Odile Jacob, 1990

22. Drewnowski A. Dietary fats: perceptions ahd preferences. J Am Coll Nutr 1990;9:431-5

23. Williams GW. Development and future direction of the world soybean market. Q J Intl Agr 1984;23:319-37

24. U.S. Department of Agriculture. U.S. fats and oils statistics, 1909-65. Statistical Bulletin No 376, ERS. Washington, DC: USDA, 1966

25. Morgan N. World vegetable oil consumption expands and diversifies. Food Rev 1993;16(2):26-30

26. Campbell TC, Chen J. Diet and chronic degenerative diseases: perspectives from China. Am J Clin Nutr 1994;59(suppl):1153S-61S

27. Lands WEM, Hamazaki T, Yamazaki KH, et al. Changing dietary patterns. Am J Clin Nutr 1990;51:991-3

28. Ling TW. Food consumption trends in Singapore. In A trimmer generation: eeting the hallenge. Proceedings of the Seminar on Healthy Weight Management in Children and Adolescents. Washington, DC: ILSI Press, 1992

29. Ministry of Agriculture, Forestry and Fisheries (Japan). Food balance sheets 1994. Internet reference: http://www.maff.go.jp

30. Popkin BM, Ge K, Zhai F, et al. The nutrition transition in China: a cross-sectional analysis. Eur J Clin Nutr 1993;47:333-46

31. Ge K. The dietary and nutritional status of the Chinese population: 1992 National Nutrition Survey. Beijing: Chinese Academy of Preventive Medicine, 1995

32. Chen $\mathrm{C}$, Shao Z. Food, nutrition and health status of Chinese in seven provinces, 1990. Beijing: China Statistical Publishing House, 1994

33. Monteiro CA, Mondini L, de Souza ALM, Popkin BM. The nutrition transition in Brazil. Eur J Clin Nutr 1995;49:105-13

34. U.S. Department of Agriculture, World Agricultural Supply and Demand Estimates (WASDE-315). Table: Vegetable oil consumption balance sheets (in million metric tons). FAS Online, July 1996

35. Mincer J. Market prices, opportunity costs, and in- come effects. In Christ CF, Friedman M, Goodman LA, et al, eds. Measurement in economics. Stanford, CA: Stanford University Press, 1963

36. Boyd SE, Shostak M, Konner M. The Paleolithic prescription: a program of diet and exercise and a design for living. New York: Harper and Row, 1988

37. Taha FA. Japan adds Western flavor to its traditional diet. Food Rev 1993;16:30-7

38. FujitaY. Nutritional requirements of the elderly: a Japanese view. Nutr Rev 1992;50:449-53

39. Matsuzaki T. Longevity, diet and nutrition in Japan: epidemiological studies. Nutr Rev 1992;50:355-9

40. Drewnowski A. Sweetness and obesity. In Dobbing J, ed. Sweetness. Springer-Verlag, London, 1987;17792

41. Drewnowski A. Sensory preferences for fat and sugar in adolescence and in adult life. In Murphy $\mathrm{C}$, Cain WS, Hegsted DM, eds. Nutrition and the chemical senses in aging. Ann NY Acad Sci 1989;561:243-9

42. Rolls BJ. Changing the preference for fat in foods. Nutr Rev 1994;52:21-3

43. Drewnowski A. Obesity and taste preferences for sweetness and fat. In Bray GA, LeBlanc J, Inoue S, Suzuki, M eds. Diet and obesity. Tokyo/S Karger, Basel: Japan Scientific Societies Press, 1988;101-12

44. Leibowitz SF, Kim T. Impact of a galanin antagonist on exogenous galanin and natural patterns of fat ingestion. Brain Res 1992;599:148-52

45. Blundell JE. Serotonin and appetite. Neuropharmacology 1984;23:1537-51

46. Drewnowski A. Opioid peptides and food preferences. Trends Food Sci Tech 1992;3:97-9

47. Schwartz MW, Seeley RJ. The new biology of body weight regulation. J Am Diet Assoc 1997;97:54-8

48. Drewnowski $A$. Linking taste perception and eating behavior to obesity. In A trimmer generation: meeting the challenge. Proceedings of the Seminar on Healthy Weight Management in Children and Adolescents. Washington, DC: ILSI Press, 1992

49. Drewnowski A. Energy intake and sensory properties of food. Am J Clin Nutr 1995;62:1081S-5S

50. Kumanyika SK. Obesity in minority populations: an epidemiological assessment. Obes Res 1994;2:16682

51. INCLEN Multicenter Collaborative Group. Body mass index and cardiovascular disease risk factors in seven Asian and five Latin American Centers: data from the International Clinical Epidemiology Network (INCLEN). Obes Res 1996;4:221-8

52. Troiano RP, Flegal KM, Kuzmarski RJ, et al. Overweight prevalence and trends for children and adolescents. Arch Ped Adal Med 1995;149:1085-91

53. Bisgrove E, Popkin BM. Does women's work improve their nutrition: evidence from the urban Philippines. Soc Sci Med 1996;43:1475-88

54. Patterson RE, Haines PS, Popkin BM. Diet Quality Index: capturing a multidimensional behavior. J Am Diet Assoc 1994;94:57-64

55. Kennedy ET, Ohls J, Carlson S, Fleming K. The Healthy Eating Index: design and applications. J Am Diet Assoc 1995;95:1103-8

56. United Nations, ACC/SCN. Second report on the world nutrition situation: global and regional results. Geneva: UN, 1992;1:1-80

57. Milio N. Toward health lessons in food and nutrition policy development from Finland and Norway longevity. Scand J Soc Med 1991;19(2):209-17 